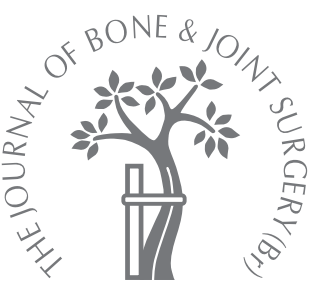

T. Okoro, P. Sell

From Leicester General Hospital, Leicester, England

T. Okoro, BSc, MBChB MRCS, Clinical Research Fellow P. Sell, BM, MSc, FRCS, Consultant Orthopaedic Surgeon

Department of Orthopaedics Leicester General Hospital, Gwendolen Road, Leicester LE5 4PW, UK.

Correspondence should be sent to $\mathrm{Dr}$ T. Okoro; e-mail: tosanwumi@hotmail.com

(C)2009 British Editorial Society of Bone and Joint Surgery doi:10.1302/0301-620X.91B4. $21861 \$ 2.00$

$J$ Bone Joint Surg $[\mathrm{Br}]$ 2009;91-B:517-21. Received 2 October 2008; Accepted after revision 9 January 2009

\title{
The prediction of outcome in somatised patients undergoing elective lumbar surgery
}

We compared a group of 46 somatised patients with a control group of 41 non-somatised patients who had undergone elective surgery to the lumbar spine in an attempt to identify pre-operative factors which could predict the outcome. In a prospective single-centre study, the Distress and Risk Assessment method consisting of a modified somatic perception questionnaire and modified Zung depression index was used pre-operatively to identify somatised patients. The type and number of consultations were correlated with functional indicators of outcome, such as the Oswestry disability index and a visual analogue score for pain in the leg after follow-up for six and 12 months.

Similar improvements in the Oswestry disability index were found in the somatised and non-somatised groups. Somatised patients who had a good outcome on the Oswestry disability index had an increased number of orthopaedic consultations (50 of 83 patients $(60 \%)$ vs 29 of 73 patients $(39.7 \%) ; p=0.16)$ and waited less time for their surgery $(5.5$ months) (SD 5.26) vs 10.1 months (SD 6.29); $p=0.026$ ). No other identifiable factors were found. A shorter wait for surgery appeared to predict a good outcome. Early review by a spinal surgeon and a reduced waiting time to surgery appear to be of particular benefit to somatised patients.

Somatisation is the tendency to experience and express somatic distress and symptoms unaccounted for by pathological findings, to attribute them to physical illness and to seek medical help for them. It is often assumed that somatisation occurs in response to psychosocial stress. ${ }^{1}$ The most important psychological disturbance in low-back pain is emotional distress. This presents clinically as the inappropriate description of symptoms and an inappropriate response to physical examination ${ }^{2}$ and appears in questionnaires as increased bodily awareness and depression. For patients with sciatica, an elevated level of distress is a risk factor for a poor outcome in the short and medium term. ${ }^{3}$ Gender, satisfaction with work, expectation of the effectiveness of treatment, and self-related health status for age have no predictive value for the outcome of subacute low-back pain. ${ }^{4}$

The Distress and Risk Assessment method score was developed as a practical means of assessing psychological disturbance in patients with low-back problems ${ }^{5}$ and has been shown to predict poor outcome in those who are treated conservatively. ${ }^{6}$ It consists of the modified somatic perception questionnaire ${ }^{7}$ and the modified Zung depression index. ${ }^{8}$ On this scale patients are classified as normal (modified somatic perception $<12$, modified Zung depression index $<17$ ), at risk (modified somatic perception $\leq 12$, modified Zung depression index 17 to 33 ), distressed somatic (modified somatic perception > 13, modified Zung depression index 17 to 33), or distressed depressive (modified Zung depression index > 33). Consequently, those who require psychological assistance can be identified early. The Distress and Risk Assessment method score has, however, failed to predict the outcome of surgery on the lumbar spine. ${ }^{5}$ Spinal surgery for radicular or stenotic symptoms is based on the patient's symptoms supported by physical examination and the appropriate radiological investigations. Somatised patients can be difficult to treat and the timing of surgery is thought to influence the outcome.

The principal aim of this study was to determine the outcome after lumbar spinal surgery in somatised patients. A secondary aim was to attempt to identify those factors which could help to predict the outcome in this subgroup of patients.

\section{Patients and Methods}

We carried out a prospective single-centre study on a heterogeneous series of patients undergoing elective surgery to the lumbar 
Table I. Comparison of outpatient attendances and percentage of orthopaedic consultations in the 46 somatised and 41 non-somatised patients

\begin{tabular}{lrl}
\hline & Somatised & Non-somatised \\
\hline Total outpatient attendances & 255 & 256 \\
Number of orthopaedic consultations (\%) & $98(38.4)$ & $84(32.8)$ \\
\hline
\end{tabular}

\begin{tabular}{|c|c|c|c|c|c|c|}
\hline & \multirow{2}{*}{\multicolumn{2}{|c|}{ Pre-operative }} & \multicolumn{4}{|l|}{ Follow-up } \\
\hline & & & \multicolumn{2}{|l|}{6 mths } & \multicolumn{2}{|l|}{12 mths } \\
\hline & ODI* (SD) & VAS $^{\dagger}$ (SD) & ODI (SD) & VAS (SD) & ODI (SD) & VAS (SD) \\
\hline \multicolumn{7}{|l|}{ Age } \\
\hline$<50$ yrs $(\mathrm{n}=30)$ & $65.5(14.8)$ & $8.9(0.91)$ & $41.2(23.1)$ & $5.6(2.8)$ & $31.9(26.4)$ & $4.4(3.2)$ \\
\hline$>50$ yrs $(n=16)$ & $62.4(10.6)$ & $7.9(1.3)$ & $41.2(21)$ & $5.13(4)$ & $34.8(20.6)$ & 4.34 (3.5) \\
\hline \multicolumn{7}{|l|}{ Gender } \\
\hline Male $(n=22)$ & $60.7(11.4)$ & $8.4(1.02)$ & $40.8(25.7)$ & $5.0(3.7)$ & $35.4(25.8)$ & $4.8(3.74)$ \\
\hline Female $(n=24)$ & $68.7(12.7)$ & $8.75(1.27)$ & $44.6(17.81)$ & $5.3(2.3)$ & $37.0(23.6)$ & $4.8(2.9)$ \\
\hline \multicolumn{7}{|l|}{ Type of distress } \\
\hline Distressed somatic $(n=17)$ & $56.4(10.7)$ & $8.4(1)$ & $39.7(22.1)$ & $5.4(2.62)$ & $36.7(24.4)$ & $5.3(3.17)$ \\
\hline Distressed depressive $(n=29)$ & $68.7(12.1)$ & $8.7(1.3)$ & $43.6(23)$ & $5.5(3.1)$ & $36.6(25.5)$ & $4.9(3.4)$ \\
\hline
\end{tabular}

spine. The study group consisted of somatised patients with a modified somatic perception $>12$, while the control group was neither somatised nor depressed.

There were 46 patients ( 22 men, 24 women) with a mean age of 44.53 years (SD 10.36) in the study group and 41 (24 men, 17 women) with a mean age of 55.68 years (SD 15.82) in the control group. We collected data using the Oswestry disability index (ODI) and a visual analogue scale (VAS) of pain in the leg at six and 12 months after surgery.

The number of consultants seen, the number of preoperative outpatient attendances, and waiting time to surgery from the definitive decision to operate were recorded. These were compared with subgroups divided by age, gender, procedure and extent of distress (somatic or depressive).

The somatised patients with the worst outcome were then differentiated from those with the best outcome using their ODI and VAS scores, and the two groups were correlated with the number of outpatient attendances and specialties involved at follow-up at six and 12 months. The minimally clinically important difference in the VAS score occurs with a reduction from the initial score of 1.7 (36.8\% sensitivity, $100 \%$ specificity). ${ }^{9}$ A good outcome using the ODI was defined as a reduction of more than 16 points from the initial score (minimally clinically important difference) while no change or an increase from the initial score indicated a poor outcome. ${ }^{10} \mathrm{~A}$ good outcome was also defined as an improvement of more than 1.7 points in the VAS score from the initial value and a poor outcome as no change or an increase in the VAS score.
Subgroups of these patients were compared for 'doctor shopping' which is a poorly defined term in the available literature. ${ }^{11,12}$ For this study we use doctor shopping to mean a quantitative assessment of the number of outpatient consultations that both somatised and non-somatised patients undergo in the period preceding surgical intervention. It was evident that doctor shopping occurred from the number of different specialties involved and health-care professionals seen.

Statistical analysis. This was carried out using Student's $t$-test and Fisher's exact test for all comparisons of significant difference. A p-value $\leq 0.05$ was considered to be significant.

\section{Results}

The number of outpatient attendances and percentage of orthopaedic consultations in the two groups were similar (Table I).

Both somatised and non-somatised patients showed the same improvement in the mean ODI at six and 12 months (somatised $v s$ non-somatised: pre-op $65 v s$ 46; six months 43 vs 22; and 12 months 37 vs 23).

Tables II and III show the correlation between subgroups of the somatised patients on the basis of age, gender, the extent of distress, the number of consultants seen and the number of pre-operative outpatient appointments. These results show no significant difference in outcome of somatised patients according to age, gender and the type of distress, therefore, these factors are not predictors of outcome. 
Table III. 'Doctor shopping' for somatic patients, related to age, gender and type of distress

\begin{tabular}{lcl}
\hline & $\begin{array}{l}\text { Mean (SD) } \\
\text { outpatient attendances }\end{array}$ & $\begin{array}{l}\text { Mean (SD) } \\
\text { consultants seen }\end{array}$ \\
\hline Age & & \\
$<50$ yrs $(\mathrm{n}=30)$ & $8.7(9.2)$ & $3.2(2.7)$ \\
$>50$ yrs $(\mathrm{n}=16)$ & $14.3(10.3)$ & $4.8(3.3)$ \\
$\mathrm{p}$-value $(t$-test) & 0.105 & 0.111 \\
& & \\
Gender & & $3.1(3.03)$ \\
Male $(\mathrm{n}=22)$ & $9.1(9.9)$ & $3.4(2.62)$ \\
Female ( $=24)$ & $10.0(7.81)$ & 0.38 \\
$\mathrm{p}$-value $(t$-test) & 0.34 & \\
& & $3.4(2.7)$ \\
Type of distress & & $3.3(2.8)$ \\
Distressed somatic $(\mathrm{n}=17)$ & $8.1(7.7)$ & 0.45 \\
Distressed depressive $(\mathrm{n}=29)$ & $10.7(9.85)$ & \\
$\mathrm{p}$-value $(t$-test) & 0.206 & \\
\hline
\end{tabular}

Table IV. Procedure-related outcome for somatised patients after follow-up for six and 12 months

\begin{tabular}{|c|c|c|c|c|c|c|}
\hline \multirow[b]{2}{*}{ Procedure undertaken } & \multicolumn{2}{|c|}{ Pre-operative ODI* (SD) } & \multicolumn{2}{|c|}{ 6-month ODI (SD) } & \multicolumn{2}{|c|}{ 12-month ODI (SD) } \\
\hline & Control & Somatic & Control & Somatic & Control & Somatic \\
\hline Decompression + discectomy (control $n=2$, somatics $n=3$ ) & $53.0(7.1)$ & $69.3(4.2)$ & $50.0(2.9)$ & $47.0(1.41)$ & $37.0(12.7)$ & $35.3(2.2)$ \\
\hline Decompression $+/$ - fusion (control $n=21$, somatics $n=22$ ) & $48.9(15.6)$ & $63.64(11.4)$ & $24.56(20.8)$ & $48.0(19.6)$ & $25.3(23.3)$ & $42.6(22.7)$ \\
\hline Anterior lumbar fusion (control $n=3$, somatics $n=4$ ) & $52.0(4)$ & $59.0(3.5)$ & $40.0(36)$ & $43.5(19.4)$ & $41.3(32.3)$ & $30.5(23.5)$ \\
\hline Discectomy (control $n=16$, somatics $n=16$ ) & $48.0(16.8)$ & $68.0(15.5)$ & $16.7(15.5)$ & $32.13(24.2)$ & $17.3(20.7)$ & $28.9(28.7)$ \\
\hline
\end{tabular}

* ODI, Oswestry disability index

Patients who underwent a discectomy did better than those having other procedures according to their ODI scores (Table IV).

Patients who had a spinal decompression attended a significantly higher number of outpatient clinics than those who had undergone a discectomy (10.65 (SD 7.41) vs 5.92 (SD 4.50) $\mathrm{p}=0.026$, Fig. 1). There was no difference in VAS of pain in the leg after follow-up for six and 12 months. According to the ODI at six months, patients who had a good outcome also had an increased number of orthopaedic consultations (50 of 83 patients $(60 \%)$ vs 29 of 73 patients $(39.7 \%)$, but this was not statistically significant $(\mathrm{p}=0.16$, Table V). At 12 months, somatised patients with a good outcome had a shorter waiting time for surgery (5.5 (SD 5.26) vs 10.1 (SD 6.29) months, $\mathrm{p}=0.026$, Table VI). By contrast, the non-somatised group of patients waited a mean of 14.8 months (SD 13.6). No difference was found in terms of the total number of consultants seen or outpatient clinics attended.

\section{Discussion}

Anxiety is related to perceptions of threat plus self-doubt about coping ability. Both the cognitive (worry, hypervigilance, focus on self) and the somatic (increased muscular tension, sleep disturbance) aspects of anxiety are evident in the descriptions of patients with chronic pain but the association between anxiety and surgical outcome is not well understood. ${ }^{13}$

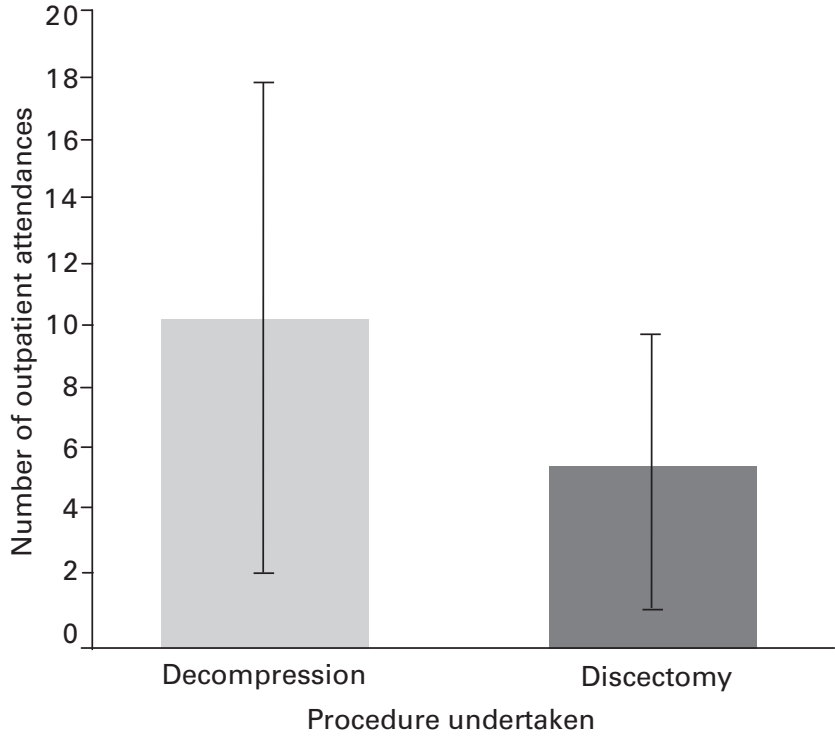

Fig. 1

Outpatient attendances vs procedure undertaken for somatised patients.

The study by Trief et $\mathrm{al}^{13}$ makes the association between employment status and surgical outcome. Patients examined at one year post-operatively who were in employment had lower levels of distress than those who were not. 
Table V. Good vs poor outcome percentage of consultations according to the Oswestry disability index (ODI) and visual analogue scale of pain in the leg (VAS) in somatised patients

\begin{tabular}{|c|c|c|c|c|c|c|}
\hline \multirow[b]{2}{*}{ Follow-up (mths) } & \multicolumn{2}{|l|}{ ODI } & \multirow[b]{2}{*}{$p$-value (t-test) } & \multicolumn{2}{|l|}{ VAS } & \multirow[b]{2}{*}{ p-value (Fisher's exact test) } \\
\hline & Orthopaedics & Other ${ }^{*}$ & & Orthopaedics & Other ${ }^{*}$ & \\
\hline \multicolumn{7}{|l|}{6 mths } \\
\hline Poor outcome & $39.7(29 / 73)$ & $60.3(44 / 73)$ & 0.16 & $31.4(32 / 102)$ & $68.6(70 / 102)$ & 0.232 \\
\hline Good outcome & $60.0(50 / 83)$ & $39.7(33 / 83)$ & & $43.8(46 / 105)$ & $56.2(59 / 105)$ & \\
\hline \multicolumn{7}{|l|}{12 mths } \\
\hline Poor outcome & $43.9(25 / 57)$ & $56.1(32 / 57)$ & 1.00 & $28(23 / 82)$ & $72(59 / 82)$ & 0.335 \\
\hline Good outcome & $45.9(28 / 61)$ & $54.1(33 / 61)$ & & $38(28 / 72)$ & $62(44 / 72)$ & \\
\hline
\end{tabular}

* other medical surgical specialties

Table VI. Comparison of mean waiting time to surgery from last outpatient review for somatised patients according to the Oswestry disability index (ODI) and visual analogue scale of pain in the leg (VAS) at follow-up at six and 12 months

\begin{tabular}{|c|c|c|c|c|}
\hline \multirow[b]{2}{*}{ Follow-up (mths) } & \multicolumn{2}{|l|}{ ODI } & \multicolumn{2}{|l|}{ VAS } \\
\hline & $\begin{array}{l}\text { Mean wait time } \\
\text { in mths (SD) }\end{array}$ & p-value (t-test) & $\begin{array}{l}\text { Mean wait time } \\
\text { in mths (SD) }\end{array}$ & p-value (t-test) ${ }^{\dagger}$ \\
\hline \multicolumn{5}{|l|}{6 mths } \\
\hline Poor outcome & $9.1(5.8)$ & 0.38 & $11.12(8.3)$ & 0.18 \\
\hline Good outcome & $8.13(9.4)$ & & $8.4(6.8)$ & \\
\hline \multicolumn{5}{|l|}{12 mths } \\
\hline Poor outcome & $10.1(6.29)$ & 0.026 & $9.5(9.18)$ & 0.25 \\
\hline Good outcome & $5.5(5.26)$ & & $7(6.06)$ & \\
\hline
\end{tabular}

Similarly, patients who reported an improvement in their back and leg pain at follow-up were less distressed before their operation. ${ }^{13}$

In the acute phase of back pain, the worries and fear may only illustrate that the patient mobilises his resources to deal with the pain, and distress may therefore not be a predictor of poor outcome. ${ }^{14}$ After a few weeks, when the pain does not improve, symptoms of depression may develop which adversely affect the patient's recovery.

The incidence of somatisation in primary care has been quoted to be approximately $26 \%{ }^{15}$ which is much higher than that seen in our series $(5 \%)$. There is a difference in the levels of anxiety and elevated distress which may not be observed in specialist clinic settings because primary-care physicians, who are likely to be more familiar with their patient population, do not report details.

Patients who have undergone discectomy do better than other subgroups of somatised patients (Table IV). In this particular group of patients, surgical outcomes are better predicted by the size and type of the herniation than by age, gender or compensation status. ${ }^{16}$ Patients who undergo spinal decompression for stenosis are older. Stricter criteria may be applied before surgical intervention is offered particularly if they have concurrent illnesses. Conservative measures such as the optimisation of pain control with analgesics, neuropathic pain medication, and the use of nerve root blocks and static exercise bikes may be used. This may account for some of the increased number of attendances.
When Hobby et $\mathrm{al}^{5}$ assessed outcome using the Distress and Risk Assessment method, they found no significant difference in the mean post-operative disability scores between the three risk groups (normal, at risk and distressed) after follow-up at six months although psychological disturbance improved. This suggests that the poor results of surgery previously reported in psychologically disturbed patients may reflect intervention in patients who did not have surgically remediable pathology. ${ }^{17}$

A study in Germany ${ }^{18}$ of 109 consecutive inpatients with low-back pain with or without sciatica assessed the influence of somatisation on the quality of life and outcome of treatment. The extent of somatisation measured by the screening for somatoform disorders questionnaire, previous in-patient treatment, the duration of illness, doctor shopping and time out of work during the preceding two years, were recorded. These were then compared with outcome measures, such as the quality of life determined by the Short Form-36 questionnaire, and VAS scores two days after admission, at pre-discharge and at follow-up of one year. The extent of somatisation and doctor shopping predicted outcome in $82 \%$ of patients in this study. Somatisation assessed at follow-up correlated negatively with all dimensions of the physical and mental quality-of-life scores $(p=0.001$ and $p<0.001)$. The authors failed, however, to define the term doctor shopping, but the Health Insurance Commission of Australia describes this as more than 30 consultations a year for any one patient. ${ }^{12}$ 
Our results suggest that an increased number of orthopaedic consultations may be predictive of outcome in somatised patients (Table V). Although this is not statistically significant, it is clinically relevant and may indicate that early consultation with a specialist is beneficial. Our impression is that the level of distress of the somatised patient diminishes with each orthopaedic consultation if their expectations are addressed and conservative measures are implemented with surgery reserved for persistent and unacceptable symptoms.

A combination of early review by a spinal surgeon and a reduced waiting time to surgery appears to be of benefit to the patient. The distressed patient should be treated promptly.

Previous studies have shown that patients do not do as well after posterior lumbar spinal surgery for degenerative disease if they have to wait for a prolonged time. ${ }^{19} \mathrm{~A}$ more recent study has shown that early surgery results in faster relief of leg pain as well as the perception of a faster recovery when compared with conservative treatment for patients with sciatica. However, at one year these differences were not significant. ${ }^{20}$ The findings in this study suggest that patients are more likely to choose surgery if they are not able to cope with their leg pain, find the natural course of recovery from sciatica unacceptably slow, and wish to minimise the time to recovery. ${ }^{20}$ Patients whose pain is adequately controlled may decide to postpone surgery in the hope that it will not be needed, without jeopardising their chance of complete recovery at 12 months. $^{20}$

Some somatised patients do well and others do badly after lumbar surgery. In the group which had a good outcome (Table VI) there appeared to be an association with a shorter wait for surgery. We suggest that the longer waiting time for surgery in the group with a poor outcome may be as a result of multiple referrals to different medical specialties before obtaining an orthopaedic opinion. Somatised patients may simply be more vulnerable with less robust coping strategies to deal with chronic pain symptoms.

There may be other relevant factors which we did not include in our study such as the level of education, previous experience of unsatisfactory consultations, understanding of the consent procedure, cultural background and expectation of outcome. Further research is needed to clarify the pre-operative factors which may be clinically useful in determining outcome in somatised patients.

No benefits in any form have been received or will be received from a commercial party related directly or indirectly to the subject of this article.

\section{References}

1. Lipowski ZJ. Somatisation: the concept and its clinical application. Am J Psychiatry 1988;145:1358-68

2. Waddell G, Main CJ, Morris EW, Di Paola M, Gray IC. Chronic low-back pain, psychological distress, and illness behaviour. Spine 1984;9:209-13.

3. Edwards RR, Klick B, Buenaver L, et al. Symptoms of distress as prospective predictors of pain-related sciatica outcomes. Pain 2007;130:47-55.

4. Karjalainen K, Malmivaara A, Mutanen P, et al. Outcome determinants of sub acute low back pain. Spine 2003;28:2634-40.

5. Hobby JL, Lutchman LN, Powell JM, Sharp DJ. The Distress and Risk Assessment method (DRAM). J Bone Joint Surg [Br] 2001;83-B:19-21.

6. Main CJ, Wood PL, Hollis S, Spanswick CC, Waddell G. The Distress and Risk Assessment Method. Spine 1992;17:42-52.

7. Main CT. The Modified Somatic Perception Questionnaire (MSPQ). J Psychosom Res. 1983;27:503-14.

8. Humphrey M. Functional impairment in psychiatric outpatients. $\mathrm{Br} \mathrm{J}$ Psychiatry 1967;113:1141-51

9. Tafazal SI, Sell PJ. Outcome scores in spinal surgery quantified: excellent, good, fair, and poor in terms of patient-completed tools. Eur Spine J 2006;15:1653-60.

10. Coelho RA, Siqueira FB, Ferreira PH, Ferreira ML. Responsiveness of the Brazilian-Portuguese version of the Oswestry Disability Index in subjects with low back pain. Eur Spine J 2008;17:1101-6.

11. Hall AJ. Logan JE, Toblin RL, et al. Patterns of abuse among unintentional pharmaceutical overdose fatalities. JAMA 2008;300:2613-20.

12. Kamien M. 'Doctor shoppers': at risk by any other name. Med J Aust2004;180:204-5.

13. Trief PM, Grant W, Fredrickson B. A prospective study of psychological predictors of lumbar surgery outcome. Spine 2000;25:2616-21.

14. Jellema P, van der Horst HE, Vlaeyen JW, et al. Predictors of outcome in patients' (sub) acute low back pain differ across treatment groups. Spine 2006;31:1699-705

15. Kirmayer LJ, Robbins JM. Three forms of somatization in primary care: prevalence. co-occurrence, and sociodemographic characteristics. J Nerv Ment Dis 1991;179:647-55.

16. Carragee EJ, Kim DH. A prospective analysis of magnetic resonance imaging findings in patients with sciatica and lumbar disc herniation: correlation of outcomes with disc fragment and canal morphology. Spine 1997;22:1650-60.

17. Waddell G, Morris EW, Di Paola MP, Bircher M, Finlayson D. A concept of illness tested as an improved basis for surgical decisions in low back disorders. Spine 1986;11:712-19.

18. Nickel R, Egle UT, Rompe J, Eysel P, Hoffman J. Somatisation predicts the outcome of treatment in patients with low back pain. J Bone Joint Surg $[B r] 2002 ; 84-$ B:189-95

19. Braybrooke J, Ahn H, Gallant A, et al. The impact of surgical wait time on patientbased outcomes in posterior lumbar spinal surgery. Eur Spine J 2007;16:1832-9.

20. Peul WC, van Houwelingen HC, van den Hout WB, et al. Surgery versus prolonged conservative treatment for sciatica. N Engl J Med 2007;356:2245-56. 